\title{
An analysis of end of life terminology in the carbon fiber reinforced plastic industry
}

\author{
David A.P. Paterson ${ }^{1}$, Winifred Ijomah ${ }^{1}$, James F.C. Windmill ${ }^{2}$
}

1 Design Manufacture and Engineering Management / University of Strathclyde 16 Richmond Street, G1 1XQ, Glasgow, Scotland, United Kingdom

2 Dept. of Electronic and Electrical Engineering / University of Strathclyde 16 Richmond Street, G1 1XQ, Glasgow, Scotland, United Kingdom

Email: david.a.paterson@strath.ac.uk,W.1.ijomah@strath.ac.uk, James.windmill@strath.ac.uk

Corresponding Author: David.a.paterson@strath.ac.uk

Keywords: Remanufacturing, recycling, composite, carbon fibre, definitions, terminology, EU directives

\begin{abstract}
While many studies and reviews into the practices conducted by industry and academia to recycle and remanufacture carbon fiber reinforced plastic (CFRP) exist, to date no investigation exists which regards the correctness of the use of terms recycling and remanufacturing. As such, this paper seeks to analyse the CFRP reuse industry's attempt to recycle and remanufacture manufacturing waste CFRP and end of life (EOL) CFRP with an emphasis on the terminology used to describe these practices. Firstly, this paper presents a justification of the importance of using EOL terminology correctly; outlining the benefits and problems associated with using the correct and incorrect terminology. This paper finds that in the case of CFRP remanufacturing, terminology is being applied incorrectly and in the case of CFRP recycling, particular care should be taken when applying the term recycled to CFRP or stating that CFRP has been recycled. Further, this paper proposes new terminology (in keeping with EU directives) which could be adopted by industry and academia working in this area. This paper also finds that in the case of remanufacture, CFRP is incapable of being remanufactured.
\end{abstract}

\subsection{Introduction}

The levels of municipal waste recorded between 1990 and 2007 by Organisation for Economic Co-operation and Development (OECD) countries rose almost year by year from approximately 537 million tonnes - 670 million tonnes; from 2007-2013 the levels have stayed at approximately within 3\% of 2007 levels (OECD, 2015). To tackle waste generation head on, the European Union (EU) has issued and continually updates/revises multiple waste related directives and targets for its members. Notable waste related directives include the waste of electrical and electronic equipment (WEEE) directive (European Parliament and 
Council 2012), the end of life vehicles (ELV) directive (European Parliament and Council 2000a), the landfill directive (European Parliament and Council 1999), the incineration of waste directive (European Parliament and Council 2000b), the waste shipment regulation (European Parliament and Council 2006) and the waste framework (WF) (European Parliament and Council 2008).

Alongside increasing regulations the demand for CFRP is also increasing, Jahn and Witten (2013) found that global market is forecast to grow 300\% between 2010 and 2020. With carbon fiber an expensive product to produce, costing up to $£ 10,000$ per ton (Marsh 2009), and although considered a complex waste type, the economic and environmental benefits (Suzuki and Takahashi 2005; Song, Youn, and Gutowski 2009; Witik et al. 2013; Howarth, Mareddy, and Mativenga 2014) of recycling are such that CFRP EOL strategies to avoid landfill receives much attention. Terminology that routinely appears within industry and academia in relation to the recycling practices includes recycled CFRP, recycled fibers, reclaimed fibers and remanufacture or re-manufacture. While many studies into CFRP recycling exist, to the author's knowledge, no study to date has examined these practices to investigate if the terms recycle and remanufacture are genuinely applicable.

This paper seeks to analyse the EOL strategies from industry and academia in reference to recycling and remanufacturing of CFRP. Prior to discussing these practices, the rationale as to why this analysis is required is presented in section 1.1. To allow this paper to be utilised in an efficient way, and for sections to be easily identifiable, the review of the current practices by industry and academia and the critical analysis of these practices are separated. As such, the review of the current practices are presented in section 2.0, the discussion section, section 3.0, documents the critical analysis with regard to remanufacture, section 3.1, and the critical analysis with regard to recycle, section 3.2. Section 3.3 presents new terminology that can be adopted by both industry and academia. The final discussion section, section 3.4, carries out an investigation on whether it is actually possible to remanufacture CFRP with section 4.0 documenting the conclusion of this text.

\subsection{The importance of correct EOL terminology}

EOL terminology, such as reuse, recycle and remanufacture, is used by various authors to describe processes in various industries, countries and sectors. Thus, the possibility exists for varying definitions of these terms to be present within literature. While in a general sense, degrees of agreement may be found between different applications EOL definitions, these various definitions tend not to be expressed in a collective uniform way and with subtle between definitions readily apparent (for instance, very often the issue of providing a warranty for a remanufactured product is omitted by some researchers - see section 3). It is also the case that some researchers may define EOL terms in a tenuous way. Examples of where generic EOL terms are used by various authors in different sectors is shown in table 1 . 
Examining now the importance of EOL terminology, it may be argued that generally, a regular incorrect application of EOL terminology has the potential to allow confusion to creep into the mind of researchers and consumers. This confusion may not appear to be significant when discussing consumables but if the product has an impact on one's life then confusion can lead to dangerous territory. For example, if we consider a pair of shoes and apply a EOL process such as repair, recondition or remanufacture; one could argue that even if doubt existed over the quality of shoes (table 3 equates typical product performance to EOL process) it may not be considered a deal breaker for the customer. However, would the same customer use their car to travel very long distances where tyres, seatbelts, airbags etc. have only been repaired, i.e. generally not at full operational capability? This answer is probably not and this highlights a real danger of incorrectly applying EOL terms; if recondition or remanufacture is used to describe repaired or recycled products the belief that remanufactured or reconditioned products are at the same level of quality as repaired or recycled products could begin to take root. Furthermore, incorrect EOL terminology reduces the potential for effective research (difficulty in collecting appropriate research samples, information and information source) and dialogue within the industry as well between the industry and key stakeholders (e.g. customers).

Looking specifically now at the importance of remanufacture, it is a generally considered principle that the public does not fully embrace remanufactured products as it does new products with (Watson 2008; Hamzaoui-Essoussi and Linton 2014; Abbey et al. 2014) presenting discussion on this. Reasons such as price, brand quality and potential prior ownership all play a role in the lack of consumer engagement. Further, these reasons tend to be complex, for example, the concept of a remanufactured product being cheaper in price than a new product may cause one customer to purchase it, but another to assume the quality is less than a new model and refrain from purchasing the remanufactured product. In addition, the rationale to purchase remanufactured goods can change from one product to the next or from one location to the next. Further, Hazen et al. (2012) found that ambiguity in the definition/description of remanufacturing process can influence the decision regarding the quality of a remanufactured product.

If the benefits of remanufacture are taken into account, benefits which include increased energy savings, increased employment opportunities, failure information fed back to manufactures and cheaper supply of products (Giuntini and Gaudette 2003; Lund and Hauser 2010), then getting the public to engage with remanufactured goods is obviously desirable. Hence, in the case of remanufacture, applying the term correctly will a) allow for an increase in remanufacturing, b) decrease in confusion, c) help reinforce the concept that the quality of a remanufactured product is always at least equal to the original and d) enable consistency in standards and quality thus forcing unscrupulous practitioners out of the industry.

There is also a potential legislative need to properly define remanufacture as a 2014 report on UK remanufacturing industry (Smith-Gillespie et al 2014) found that current legislation was not geared towards encouraging organizations to remanufacture. As such, it can be said that any potential future incentives to encourage remanufacturing could only be available to organizations that actually perform true remanufacturing. It is also the case that an incorrect/ambiguous definition can lead to difficulties in gauging the industry; Lund and 
Hauser (2010) state that when the American remanufacturing industry was gauged in a previous paper, (Lund 1996), its size was dramatically over estimated. This over estimation was caused by relying on information from membership lists of trade associations, where high numbers of members were only conducting remanufacturing by a very liberal definition - the definition to describe remanufacture did not separate remanufacture from recondition and so reconditioners were counted alongside remanufactures. It was also the case that the directors of these trade associations provided too high an estimate of remanufactures in their sector but outside of their membership.

Staying with the theme of misrepresenting the true remanufacturing industry and looking specifically at CFRP, in their examination of the environmental benefits of CFRP recycling against incineration and landfilling Witik et al. (2013) advised that future work associated with the remanufacturing of CFRP should provide data on energy requirements, the resources used, waste produced and the emissions generated. If the incorrect EOL terminology is used (for example remanufacture) the environmental benefits associated with a particular strategy, could actually be environmental benefits associated with another EOL strategy.

Looking now at the importance of defining recycle and other EOL terms correctly, justification can be found in the fact that terms such as recycle, reuse, re-use, recovery, waste etc., are routinely discussed in directives and legislation. The waste framework directive, (European Parliament and Council 2008), article 4 point 1 states' The following waste hierarchy shall apply as a priority order in waste prevention and management legislation and policy: (a) prevention; (b) preparing for re-use; (c) recycling; $(d)$ other recovery, e.g. energy recovery; and (e) disposal'. And the end of life vehicles directive, (European Parliament and Council 2000a), article 7 point 2(b), states' no later than 1 January 2015, for all end-of life vehicles, the reuse and recovery shall be increased to a minimum of $95 \%$ by an average weight per vehicle and year. Within the same time limit, the re-use and recycling shall be increased to a minimum of $85 \%$ by an average weight per vehicle and year'. From this text, it is readily apparent that using terminology such as re-use, recovery and recycle correctly would allow companies or organizations to better comply with both existing and any new directives issued.

Additionally, if consulted to take part in discussions to create new directives or the national legislation that arise from these directives, applying EOL terminology correctly allows organizations to represent their practices and viewpoints more accurately. To exemplify this consider Witik et al. (2013), who state that the aforementioned EU waste hierarchy is only to be considered a good rule of thumb when dealing with CFRP. If a future strategy for CFRP waste management was conceived, noting that at present CFRP does not have a specific directive but instead is regarded generally as waste or vehicle component, then a proper definition of terminology is called for, thus strengthening the case that practices, terminology and products are required to be defined correctly.

At this point, we suggest that an investigation into the practices conducted by industry and academia in relation to CFRP is required. This investigation will result in several outcomes, including a decision as to whether remanufacturing is occurring, raising remanufacturing awareness within this sector, a decision as to whether recycle is applicable 
to CFRP and carbon fibers, a reduction in any potential confusion between EOL treatments, and if applicable, a proper definition of the products created in this emerging sector.

\subsection{Instances where 'recycle' and 'remanufacture' appear in industry and academia for CFRP}

The first example is a division of AdTech International Incorporated, 'Carbon Fiber Remanufacturing TM' (CFR) - noting that AdTech International Incorporated date back to 1997 and have a raison d'etre of developing efficient solutions to the problem of excess material that is generated by industry and commerce. According to CFR they are a global leader in carbon fiber remanufacturing and were established to develop extensive recycling programmes for high-grade carbon fiber, carbon fiber that is currently in service across manufacturers of composites and aerospace companies globally. CFR obtains excess or scrap carbon fibers that are generated as part of the manufacturing process. These fibers, deemed reclaimed fibers, include fiber from tow that has fallen off tubes at some stage. CFR perform applications such as 'detangling, milling and cutting' on these fibers allowing them to be used again for industry specific applications. The fibers, now called remanufactured carbon fibers, are stated to have retained their virgin properties, are available at discount prices and have the ability to be used in construction of CFRP. Interestingly the term recycle is also used by CFR; it is used when describing the overarching operation of what they perform, for example, a particular recycling programme offered by CFR includes providing remanufacture of carbon fibers. CFR particulars include a recycling capability of 130,000 lbs per month, 3 industrial scale warehouses (one at 60,000 square feet and two at 100,000 square feet) a $300,000 \mathrm{lbs}$ per month detangling capacity, an overall precision cutting capacity of 280,000 lbs per month and a 60,000+ lbs per month yarn manufacturing capacity.

The second example is ELG Carbon Fiber limited, noting here that the initial incarnation of the company dates back to 2003, and that they are similar to CFR in that they also seek to collect carbon fiber deemed as industry waste or scrap. With a capacity to handle 2000 tonnes of carbon - composite waste ELG seek to recycle dry fibers (similar to CFR), cured and uncured pre-preg and also laminate, which of course includes CFRP. On reception of scrap, or EOL carbon-composite, ELG state that the material is recycled into a new varied product line, which includes both milled fiber and chopped fiber. EOL do not state that recycled carbon fiber approach the qualities of the virgin counterparts. |The third example is Fraunhofer (www.fraunhofer.de/en.html), a large application-oriented research organization based in Europe. A particular Fraunhofer institute - the Institute for Manufacturing Technology and Advanced Materials - actually offers a remanufacturing course. The course spanning 40 hours (approximately 1 week) gives instructions on how to repair carbon fiber

reinforced plastics. Other notable industrial examples in the recycling of carbon fiber include the major efforts from both the TARMAC Aerosave and AFRA programmes.

AFRA are the aircraft fleet recycling association, which comprise approximately 70 members, noting that Boeing who are a founding member state that they are committed to reaching $90 \%$ aircraft recyclability. They further state that if the 2 million pounds of carbon 
fiber scrap that was expected to be generated in 2014 is recovered and recycled and used in exchange of virgin carbon fiber, significant electricity savings could be generated - energy savings which could power 175,000 typical houses per year (Carberry 2008). Looking now at the Tarbes Advanced Recycling and Maintenance Aircraft Company (TARMAC), they state that they are Europe's largest aircraft storage organization (capability for 250 aircraft) and are committed to recycling $90 \%$ by weight of decommissioned aircraft. Further, Airbus, a founding member of TARMAC Aerosave, collaborated with CFR-Valley Stade Recycling $\mathrm{GmbH} \& \mathrm{Co} \mathrm{KG}$ in 2010 to create a 1000 tonne/year recycling plant designed to recover scrap carbon fiber from decommissioned aircraft. Other notable industrial efforts in this field are efforts from the Materials Innovation technologies (MIT) and the CRESIM project from Canon group. Heil (2011) presents a similar analysis of this industry and attention may be turned here for additional reading.

Turning now to academia, significant literature reviews concerning the recycling of CFRP can be found (Pickering 2006; Pimenta and Pinho 2011; Yang et al. 2012; Perry et al. 2012; Asmatulu, Twomey, and Overcash 2013; Oliveux, Dandy, and Leeke 2015) and it is found that within the field of CFRP recycling, a clear separation is made between two distinct forms of recycling. The first type of recycling is mechanical recycling and the second type of recycling is fiber reclamation.

Looking first at mechanical recycling, this involves taking the CFRP and performing techniques such as grinding, crushing and milling. Once the CFRP is crushed, milled and ground the segregation of the fibers and the resin can take place. Noting here that owing to structure of the fibres and possible inclusion of trace elements of resin, after mechanical recycling the amount of pure carbon materials produced may be reduced not be as high as the original fibres.

Typical applications for mechanical recycled CFRP include use as filler or for resin reinforcement in new composites. Mechanical recycling, however, does not allow the original fiber part of the CFRP to be reclaimed in its original form and so future mechanical tests have to be conducted on the composite level. While composite mechanical behaviour is complex, in general, a mechanically recycled composite suffers from significant fiber breakage and a random fiber arrangement. This leads to reductions in the mechanical strength of composite made using these type of recyclate. This was shown by Ogi et al. (2007) and Okayasu et al. (2013) who took crushed CFRP and mixed this with acrylonitrile butadiene-styrene (ABS) resin to create new CFRP, and subsequently conducted a series of tests to understand fundamental properties such as tensile modulus, strength and fracture behaviour. To give an idea of the scale of the crushing, milling and grounding, (Ogi et al 2007) crush 3.4 x $0.4 \mathrm{~mm}^{2}$ pieces of virgin CFRP and the resulting average fiber length resulting from this process is around $200 \mu \mathrm{m}$ (which is significantly smaller than the original fibres which measure the length of the surface of the sample). Alongside random fibre arrangement and fibre length, fibre volume may also play a role in the composite properties. That is, implanting chopped and powered fibres that include trace elements of resin, with new resin will in general record a lower volume of fibre content than the original. Attention may be turned to Pimenta and Pinho (2011) for discussion on this.

Looking now at fiber reclamation, unlike mechanical recycling, this seeks to recover the fibers from CFRP by means of thermal and chemical processes - these processes seek to 
destruct the matrix (noting that energy or molecules from the matrix can potentially be recovered). Within academia a number of options have been outlined that can facilitate fiber reclamation, namely pyrolysis, oxidation in a fluidised bed and chemical recycling. Looking first at pyrolysis, this is where the CFRP is subjected to significant heat, up to $750{ }^{\circ} \mathrm{C}$, in an atmosphere which is absent of oxygen. Regarding the recovery of energy, Shi, Kemmochi, and Bao (2012) state that when performing pyrolysis on CFRP, the 'resin breaks down into lower molecular weight organic substances (gasses)' or put another way the energy associated with the matrix may be recovered.

The oxidation in the fluidised bed approach takes CFRP scrap and lays it on a bed of silica, which is itself on a metal mesh. A flow of hot oxygen is fed through the CFRP resulting in the decomposition of the matrix and ultimately the separation of matrix and fibers. The fibers and oxidised molecules are carried in the airflow (noting that the heavier metallic elements are not carried in the airflow) with a cyclone used to separate the fibers from the airflow. Similar to pyrolysis the energy of the matrix is recoverable - the resin is fully oxidised in an afterburner to allow for this. The final methodology for reclaiming fibers is chemical treatment.

Chemical treatment concerns exposing the CFRP to a reactive medium, such as supercritical fluids. Chemical recycling causes monomers, which are the building blocks of polymers to form groups known as oligomers. The creation of these oligomers leads to the separation of matrix and fibers, allowing the fibers to be collected, noting that many mediums exist to perform chemical recycling and that the energy from the matrix is also recoverable in this method.

Outside of mechanical based and fiber reclamation based, recycling terminology also appears in literature as a way to re-use (almost directly) CFRP. Asmatulu, Twomey, and Overcash (2013) state that an approach labelled as 'direct structural composite recycling' is where large EOL composite products are cut into smaller size sections, which can be used directly in smaller composite components. It is also the case that the concept of remanufacture is also discussed within academia (Pimenta and Pinho 2011, 2012; Shi et al. 2012; Perry et al. 2012; Morin et al. 2012; Oliveux, Dandy, and Leeke 2015) all discuss using recycled carbon fibers (noting that recycled exclusively means fiber reclamation and not mechanically recycled CFRP) to generate new CFRP or as described in literature to 'remanufacture' CFRP. That is, reclaimed fibers are re-impregnated with new resin to 'remanufacture' new CFRP.

It is also often the case within the literature that remanufacture is labelled as a subset of recycling in that the remanufacturing process is part of the recycling process. For example, Pimenta and Pinho (2012) state that that the process of re-impregnating reclaimed fibers with resin (dubbed composite remanufacture) is the second phase of the fiber reclamation stage. Noting, that the re-impregnation of resin is performed in a variety of ways, which include injection moulding and BMC compression. Shi et al. (2012) also discuss using recycled carbon fibers to generate new composite material, they state 'It is possible to recycle fiber from FRP, and to remanufacture them into high-value R-FRP for reuse' (noting that FRP and R-FRP were previously defined in the particular paper as fiber reinforced plastic and recycled-fiber reinforced plastic. In relation to fibre reclamation processes and recycling processes of CFRP, Pimenta and Pinho (2011) provide an excellent and comprehensive study 
of the nuances between each process. As this text is not strictly concerned about the steps involved in these processes, but instead is more focused on the resulting products that emerge from these processes, i.e. reclaimed fibres or crushed fibres, attention can be turn to this work, for further reading.

Additionally, the term remanufacture has also been used within literature to describe the process of taking waste CFRP and performing splitting, hot and cold forming to mould the scrap CFRP into new shapes, with up to $50 \%$ of original mechanical properties maintained (Adams et al. 2014). Table 2 presents a summary of key recycling and remanufacturing terms/themes documented within academia and industry.

\section{INSERT TABLE 2 HERE}

Having now identified instances in industry and academia where the terms recycled and remanufactured CFRP are discussed, and often appear to overlap each other, a critical evaluation of these instances can now take place.

\subsection{Discussion}

In this section a critical analysis of remanufacturing and recycling of CFRP, as described by academia and industry, is presented. Prior to this, to allow for a frame of reference, remanufacturing, and recycling operations are briefly discussed.

\section{$\underline{\text { Remanufacture }}$}

A definition of remanufacturing which is in keeping with British standards (Matsumoto and Ijomah 2013) (BSI 8887-2:2009, 2009) governing the term remanufacture can be cited from literature:

'remanufacturing is the only end of life process where used products are brought at least to Original Equipment Manufacturer (OEM) performance specification from the customer's perspective and at the same time, are given warranties that are equal to those of equivalent new products' (Ijomah 2002)

Remanufacture is thus considered a different process from repair and recondition, and the hierarchal relationship between these three strategies outlined in table 3 . For specific processes, practices, protocols and benefits involved in remanufacturing, attention may be drawn to (Lund 1985; Ijomah 2002; King et al. 2006; Ijomah et al. 2007; Lund and Hauser 2010; Gutowski et al. 2011) 


\section{$\underline{\text { Recycling }}$}

Recycling is often used generically to discuss various ways of using EOL components. The general usage of the term recycle is very often incorrect. The explanation presented here is in keeping with literature, (Sundin 2004; King et al. 2006; Gray and Charter 2008) recycling can be regarded as a series of processes where materials are collected, processed and then reused. A key aspect of recycling is that the products being processed are returned to raw materials form and the resource and embodied energy, known as emergy, used to create the product is thus lost. Further, recycled products may be used to create the same product (closed loop recycling) or different products (open loop recycling). Figure 1 visualizes the concept of recycling and a recycled product.

\section{INSERT FIGURE 1 HERE}

Having defined both remanufacture and recycle the critical analysis of these terms in relation to CFRP is considered. An evaluation of remanufacture as applied with CFRP is presented first.

\subsection{Critical analysis on the applicability of the term remanufacture to CFRP}

To analyse the practices within industry and academia, key aspects of the remanufacturing process are presented with industrial and academic efforts evaluated against them.

\section{Have standard remanufacturing protocols been followed?}

No evidence from literature or industry has been recorded documenting that used CFRP (CFRP acts as core in this instance) has been received, striped, had its component parts cleaned and returned to as new standard (or replaced) and then reassembled.

Is the quality equal (or better) to that of the original?

It is generally the case within literature (Pimenta and Pinho 2011,2012; Adams et al. 2014; Oliveux, Dandy, and Leeke 2015) that the mechanical performance of CFRP (created by remanufacturing) is stated as being inferior to that of virgin CFRP. In some instances, properties can approach virgin like properties, but issues such as fiber adhesion, fiber degradation and breakages and non-ideal recycling processes account for mechanical degradation.

Looking at carbon fibers in isolation, CFR state that their remanufactured carbon fibers retain their virgin like properties. This concept poses an interesting question; why is academia finding difficulty when industry, CFR, state that virgin like properties are maintainable? The answer to this is that CFR are reclaiming and sorting fiber that is manufacturing waste or scrap, i.e. fiber that has not yet been used. If the fiber has not been 
used or processed, it is by definition not possible to remanufacture these fibers. CFR sort/detangle/cut reclaimed fibers and call them remanufactured. This is not remanufacturing.

Is remanufactured CFRP issued with a warranty equal to that of the original?

No evidence exists within academia or industry that warranties equal to that originally supplied are issued with remanufactured CFRP. In the case of CFR, if the fibers have not been used they cannot have not been issued with a warranty ergo, the warranty given (if any) to the remanufactured fibers is the first warranty issued for this product.

$\underline{\text { Is remanufacturing discussed as an individual EOL process? }}$

Within industry and academia, text has shown that remanufacturing is routinely regarded as part of the recycling process, which is of course not the case. CFRP that has been created through remanufacturing is typically called recycled CFRP, which given the accepted understanding of remanufacturing is a nonsensical concept (remanufacturing retains emergy, recycling destroys emergy). Remanufacturing and recycle are separate EOL strategies and while, it may be possible to recycle parts of a remanufactured product (discarded parts for example), remanufacture is not considered part of recycling processes.

\section{$\underline{\text { Decision }}$}

While industry and academia both use the term remanufacture, it is the generally the case that remanufacture is used to describe the process of reusing reclaimed carbon fibers either by themselves or in a new CFRP. It is therefore clear at this point that no actual remanufacturing occurs. However, it is also the case that no evidence exists to suggest that remanufacturing terminology is deliberately being used incorrectly. Judging by the fact that the term remanufacture is being used in a way which bears little resemblance to its true meaning, a reasonable conclusion would be that some CFRP based researchers in academia and practitioners within industry may simply be unaware of the concept of a true remanufactured product. Figure 2 is presented to demonstrate graphically the clear difference between a remanufactured product and what is currently described as remanufacturing by industry and academia in relation to CFRP.

\section{INSERT FIGURE 2 HERE}

\subsection{Critical analysis on the applicability of the term recycling to CFRP}

Literature, including this text, has shown that in general, recycling of CFRP is grouped into two groups, group 1) mechanical recycling and group 2) fiber reclamation. These two groups will be evaluated separately from each other in the forthcoming text.

Mechanical recycling 
Figure 1 demonstrates that the recycling of discarded products results in the creation of material/energy that may be used in exchange for virgin materials when manufacturing new products. Additionally, it has been stated that emergy is lost when performing recycling; it is this fundamental concept that allows the term mechanical recycling to be used in the context of CFRP. The fibers and resin that were originally part of the virgin CFRP are no longer in the same form, they have been crushed, milled and ground into a form which can then be used to create a new product; the new product being part used material (crushed fibers) and part new product (impregnated with new resin). The composite emergy has been completely lost during this process, allowing mechanical recycling to be regarded as a legitimate form of recycling with no issues arising.

\section{$\underline{\text { Fiber reclamation }}$}

Recycling process associated with fiber reclamation are slightly more complicated to analyse owing to the fact that fiber reclamation is itself considered a recycling process by industry and academia, and that the creation of new products from reclaimed fibers is considered recycled CFRP. Both fiber reclamation and recycled CFRP are examined with the former evaluated first.

Considering a discarded product that is recycled, the emergy of the product is lost leaving only the pre-processed materials or energy from the creation of these materials. The strategy within industry and academia to reclaim fibers, deemed as a recycling process, is to extract fibers from discarded CFRP with as little damage or change to the fibers as possible. The issue here is that the fibers retain significant amounts of their emergy and this causes a conflict in terms; how can a recycled product, i.e. reclaimed fibers, retain emergy? Therefore, recycled is not an appropriate term to use to describe reclaimed fibers as recycling destroys emergy and reclaimed fibers retain their emergy. It is true however, that in an extremely strict interpretation of recycling, one could state that not all the emergy remains after reclamation, typically fibers lose their sizing and CFRP is often cut into smaller manageable sections prior to reclamation. However, in comparison to the energy required to produce virgin fibres, 183$286 \mathrm{MJ} / \mathrm{Kg}$ (Song, Youn, and Gutowski 2009), any loss of emergy through size reduction and lack is sizing is not considered significant in this instance.

Moving on to consider recycled CFRP, previous work has shown that fiber reclamation processes such as heat treatment and chemical treatment allow for the energy of the matrix to be retained. As such, heat treatment or chemical treatment, designed to release the fibers from the matrix and destroying the emergy of the composite, i.e. (Song et al 2009) found that autoclave moulding alone accounted for an estimated $29.1 \mathrm{MJ} / \mathrm{Kg}$ additional energy to be expired, could both be considered recycling processes. This concept is effectively identical to mechanical recycling; where mechanical recycling performs crushing, grinding and milling and fiber reclamation based recycling performs heat treatment or chemical treatment.

Critically however, the term recycled CFRP should be avoided for two reasons. The materials used to create the product, reclaimed fiber and virgin resin, are not themselves recycled products and the definition of recycled CFRP itself has no real meaning (even if this definition was taken in the general sense to mean products created from recycled material, 
this would only be referring to the recycled matrix element of the original product). An additional validation of the above arguments can be developed by examining EU directives and guidance. The WF directive, (European Parliament and Council 2008), defines the terms recycling as,

'any recovery operation by which waste materials are reprocessed into products, materials or substances whether for the original or other purposes. It includes the reprocessing of organic material but does not include energy recovery and the reprocessing into materials that are to be used as fuels or for backfilling operations'

To characterise all the operations of recycling would be virtually impossible, and as definitions are often general descriptions of practices, the potential exists for different interpretations. To assist with such problems, the EU has also issued additional guidance, (European Commission 2012). In this guidance the practice of recycling is expanded upon,

'only the reprocessing of waste into products, materials or substances can be accepted as recycling. Processing of waste which still results in a waste which subsequently undergoes other waste recovery steps would not be considered recycling, but pre-treatment prior to further recovery.'

As such, if mechanical, heat and chemical treatments are regarded as legitimate forms of recycling CFRP (which literature, including this paper, subscribes to), then the resulting fibers that are created from recycling cannot be considered waste. If fibers are not considered waste, they cannot therefore be recycled in this context (recycling operations can only be conducted on waste).

\section{$\underline{\text { Decision }}$}

This text has shown that in terms of mechanical recycling, the term recycle is correctly applied with no issues arising. However, reclaimed fibers are not recycled fibers and should not be regarded as such. The final issue of creating CFRP from reclaimed fibers and labelling it, recycled CFRP is a more complex issue. While the practices involved in fiber reclamation such as pyrolysis and chemical treatments are recycling operations, new products created from reclaimed fiber are not in general recycled products and so the term recycled CFRP is should be avoided.

It has been shown that within industry and academia, in relation to CFRP, no evidence of remanufacturing exists, and that in the case of recycle, the term should not be applied to reclaimed fibers or products created from reclaimed fibers. We now propose a new terminology to describe these industrial and academic efforts.

\subsection{Proposal of new terminology}

When deciding upon new accurate terminology to describe CFRP constructed from reclaimed fibers, the immediate consideration is to examine current EU directives. The idea here is that the current directives which CFRP acts under (major directives include the ELV directive, WF directive and WEE directive), could already contain the required accurate terminology to describe the practices conducted. Adopting this method, potential terminology defined in the 
WF directive, (European Parliament and Council 2008), is re-use, recovery and preparing for re-use. These are defined respectively,

're-use' means any operation by which products or components that are not waste are used again for the same purpose for which they were conceived;'

'recovery' means any operation the principal result of which is waste serving a useful purpose by replacing other materials which would otherwise have been used to fulfil a particular function, or waste being prepared to fulfil that function, in the plant or in the wider economy. Annex II sets out a non-exhaustive list of recovery operations;'

“preparing for re-use' means checking, cleaning or repairing recovery operations, by which products or components of products that have become waste are prepared so that they can be re-used without any other pre-processing;'

Immediately, the terms recovery and preparing for re-use can be dismissed - dismissed because if thermal and chemical treatments are defined as recycling then fibers cannot be regarded as waste. If fibers are not regarded as waste then the 'recovery' terminology cannot be used to describe the fiber reclamation based products (but can be used to describe the fiber reclamation process incidentally). Preparing for re-use also falls foul of this subtle distinction, as while the fiber reclamation process can be regarded as a preparing for re-use operation, products created from reclaimed fibers cannot be regarded as preparing for re-use operations (reclaimed fibers are not regarded as waste). This leaves the terminology re-use. Re-use states that products or components that are not waste are used again for the same purpose for which they were conceived. To clear any doubt that may be cast over this terminology, additional guidance issued from the EU, allows for some repairing to be carried out (in this case, a sizing operation for example), while still regarding the product as re-used.

'...Re-use is a means of waste prevention; it is not a waste management operation. For example, if a person takes over a material, e.g. piece of clothing, directly from the current owner with the intention of re-using (even if some repairing is necessary) it for the same purpose, this comprises evidence that the material is not a waste'

(European Commission 2012)

Therefore, at this stage, at least in terms of compliance with the WF directive (CFRP having no specific directives of its own) the term re-use is the most applicable to describe CFRP created from reclaimed fibers. That is, reclaimed fiber based CFRP currently described, as recycled CFRP, is more accurately described as re-used fiber CFRP (rf-CFRP) or CFRP from re-used fibers (CFRP-rf). Further weight is added to this terminology in the sense that the ultimate goal of CFRP recycling is to extract the fibers with effectively no damage at all occurring to the fibers (the breakage of CFRP into smaller manageable sizes is still anticipated however).

As CFRP has no legislation of its own and acts under more than one directive it is appropriate to test the terminology against other major directives that CFRP acts under. The ELV directive, (European Parliament and Council 2000a), defines reuse as

'any operation by which components of end-of life vehicles are used for the same purpose for which they were conceived;' 
The WEEE directive, (European Parliament and Council 2012), defines re-use as a citation from the WF directive, repeated again for clarity,

"re-use' means any operation by which products or components that are not waste are used again for the same purpose for which they were conceived;'

Thus, adopting the term rf-CFRP to describe CFRP created from reclaimed fibers is therefore also acceptable in accordance with the ELV directive and the WEEE directive. It should also be noted that the re-use terminology is generally not applicable when describing CFRP made from mechanically recycled CFRP. This is because there is a significant loss of the structural integrity of the fibers since mechanical recycling crushes chops and mills the fibers into far smaller pieces, and in some cases a powder. Thus, by adopting rf-CFRP a clear distinction between mechanical recycling and fiber reclamation is created. That is, rf-CFRP only describes reclaimed fiber based CFRP (at present, terminology conventions allow for both reclaimed fiber CFRP and chopped, crushed and milled based CFRP to be classed as recycled CFRP).

Another benefit from adopting this terminology is that any potential confusion and ambiguity over the concept/definition of recycled CFRP may be reduced, therefore a potential barrier to a successful implantation of a future CRFP EU directive (should the EU be required to create one) would be eliminated. For instance, without being involved in industry and its research, someone would struggle to state that a recycled CFRP is created by recycling the matrix element of a current composite and using this energy to help power the reclamation of fibers from the same matrix to then implant these reclaimed fibers into a new matrix, thus creating recycled CFRP.

Adopting the method of examining EU directives to classify reclaimed fiber based CFRP as rf-CFRP also serves to build on the work carried out by Glavič and Lukman (2007) In their review of sustainability terms and definitions, reuse is quoted as,

'The reuse means using waste as a raw material in a different process without any structural changes'

This definition of reuse is taken by the authors from the European Environmental Agency (EEA) glossary and it is directly in conflict with the definitions given in this paper. Re-use is not regarding as taking waste and reusing it, it is regarded as taking products that are not waste and reusing them (as defined by the WF directive). Examining a fresh definition from the EEA glossary, reuse is quoted as,

\section{'Material reuse without any structural changes in materials'}

Although the modern definition of reuse eliminates the notion of products being waste prior to reuse, this definition is still problematic owing to the insistence of no structural change. It has already been shown that under the WF directive, even if something is repaired (which is by definition a structural change), it can still be regarded as product re-use. Hence, it may be that case that a) re-use is defined separately from reuse (re-use is not included in glossary) or b) the glossary is only approximate definitions. Taking a) and b) into account, it can be said that to conduct further studies in this field, definitions should be examined on a directive level only.

\subsection{Can CFRP ever be remanufactured?}


Remanufacture as defined by Ijomah (2002) is not occurring within the field of composite EOL strategy. Therefore, an analysis of whether it is actually possible to remanufacture composite is now presented. The fundamental requirements of any remanufacturable product is that the products core (remanufactured products must contain a core) can be disassembled, have it components parts repaired (or replaced) back to original specification standard and then be reassembled. If CFRP can truly be remanufactured then it must meet these minimum requirements. The first requirement that must be met is the existence of a core. CFRP is of course a composite and it can therefore be argued that the fibers act as the core, the resin acts as the core or the combination of both fibers and resin (the CFRP itself) act as the core. The next requirement is that the core can be disassembled and then reassembled. If we assume that the resin acts as the core alone, then the core cannot be disassembled and successfully reassembled, thus CFRP is not remanufacturable. If we assume the fibers act as the core alone, then the core cannot be disassembled and successfully reassembled, thus CFRP is not remanufacturable. If we assume the fibers and the resin together act as the core then the same conclusion of CFRP not being truly remanufacturable is still met - the fiber and the resin are not capable being disassembled and then being restored to their original specification.

Thus, it can now be stated that CFRP cannot be remanufactured, however, this does not preclude a product constructed (in part) out of CFRP from being remanufactured. For instance, if the fuselage of an aircraft is composed of an under laying structure with discrete panels of CFRP attached, as in some modern Airbus airframes, it be argued that the fuselage could be presented as the core with the CFRP panels acting as components of the core. In this instance, the product could be remanufactured but the CFRP could not.

\subsection{Conclusion}

This paper has investigated the industrial and academic practices to reuse EOL CFRP, in particular the recycling and remanufacture of EOL CFRP. It has been shown that while CFRP is capable of being recycled, terminology such as recycled CFRP, recycled fibers and remanufacture (or re-manufacture) are not in general applicable terms for use in this sector.

Evidence for this viewpoint is found by analysing industrial and academic practices in relation to remanufacturing and recycling definitions. It was found that no evidence exists of remanufacturing taking place, that reclaimed fibers are not the same as recycled fibers, and the term recycled CFRP is an ambiguous way of describing CFRP created from reclaimed fibers. Justification as to why the correct use of terminology is desirable has also been demonstrated, with concepts such as raising remanufacturing awareness, removing potential blocks to gauging the remanufacturing industry, successful compliance with existing EU directives, ensuring companies/organizations are in best position to help create new directives and general reduction in EOL confusion being discussed.

Having shown, that terms such as remanufacture and recycled CFRP are to be avoided, new terminology to describe CFRP created from reclaimed fibers has been presented. This new terminology is re-used fibre CFRP (rf-CFRP) or CFRP from re-used fibers (CFRP-rf). The term re-use complies with existing EU regulations that CFRP acts under and is a more accurate way to describe reclaimed fiber based CFRP. It is also been shown that rf-CFRP is not applicable for CFRP created from crushed, milled and ground 
fibers. Thus an additional benefit of the new terminology is that a clear separation between crushed, milled and ground fiber based CFRP products and fiber reclamation based CFRP is created (at present, recycled CFRP may be used to describe CFRP from crushed, milled and chopped fiber based CFRP as well as reclaimed fiber based CFRP). Additionally, an analysis of the remanufacturability of CFRP has also been presented. It was found that CFRP is incapable of being remanufactured.

This paper has also shown that when discussing specific sustainability terminology within literature, it may be best practice to define these terms in the context of directives/legislation. It is advised that future studies into sustainability concepts/products/practices should take into account that possible existing directives/legislation may exist in which the same term is defined differently (with differences being potentially subtle) in separate directives.

\section{References}

Abbey, James D., Margaret G. Meloy, V. Daniel R Guide, and Selin Atalay. 2014. "Remanufactured Products in Closed-Loop Supply Chains for Consumer Goods." Production and Operations Management 24 (3): 488-503. doi:10.1111/poms.12238.

Adams, R. D., Andrew Collins, Duncan Cooper, Mark Wingfield-Digby, Archibald WattsFarmer, Anna Laurence, Kayur Patel, Mark Stevens, and Rhodri Watkins. 2014. "Recycling of Reinforced Plastics." Applied Composite Materials 21 (1): 263-84. doi:10.1007/s10443-013-9380-1.

Asmatulu, E., J. Twomey, and M. Overcash. 2013. "Recycling of Fiber-Reinforced Composites and Direct Structural Composite Recycling Concept." Journal of Composite Materials 48 (5): 593-608. doi:10.1177/0021998313476325.

Bakar, M., and S. Rahimifard. 2008. "Ecological and Economical Assessment of End of life Waste Recycling in the Electrical and Electronic Recovery Sector." International Journal of Sustainable Engineering 1 (4): 261-77. doi:10.1080/19397030802576825.

BSI 8887 - 2:2009, 2009, "Design for Manufacture, assembly, disassembly and end-of-life processing (MADE).Terms and definitions", Produced by British Standards Institute technical product specification committee (TDW/004/0-/05 Design for MADE BSI), British Standards Publications, Southham (2010).

Carberry, W. 2008. “Aero.” Boeing Commercial Magazine. http://www.boeing.com/commercial/aeromagazine/articles/qtr_4_08/pdfs/AERO_Q408. pdf

Cheung, Wai M., Robert Marsh, Paul W. Griffin, Linda B. Newnes, Antony R. Mileham, and John D. Lanham. 2015. "Towards Cleaner Production: A Roadmap for Predicting Product End-of-Life Costs at Early Design Concept." Journal of Cleaner Production 87: 431-41. doi:10.1016/j.jclepro.2014.10.033 
European Commission, 2012. "Guidance on the interpretation of key provisions of Directive 2008/98/EC on waste."

http://ec.europa.eu/environment/waste/framework/pdf/guidance_doc.pdf.

European Parliament and Council, 2012. "Directive 2012/19/EU of the European Parliament and of the Council of 4 July 2012 on waste electrical and electronic equipment (WEEE)." Official Journal of the European Union L 197/38. http://eurlex.europa.eu/LexUriServ/LexUriServ.do?uri=OJ:L:2012:197:0038:0071:en:PDF

European Parliament and Council, 2008. "Directive 2008/98/EC of the European Parliament and of the Council of 19 November 2008 on waste and repealing certain directives" Official Journal of the European Union, L 312/3 http://eurlex.europa.eu/legalcontent/EN/TXT/PDF/?uri=CELEX:32008L0098\&from=en

European Parliament and Council, 2006. "Regulation No 1013/2006 of the European Parliament and the Council of 14 June 2006 on shipments of waste." Official Journal of the European Union, L 190/1. http://eur-lex.europa.eu/legalcontent/EN/TXT/PDF/?uri=CELEX:32006R1013\&from=en

European Parliament and Council, 2000a. "Directive 2000/53/EC of the European Parliament and Council on 18 September 2000 on End-of Life Vehicles." Official Journal of the European Communities L269/34.

http://eur-lex.europa.eu/resource.html?uri=cellar:02fa83cf-bf28-4afc-8f9feb201bd61813.0005.02/DOC_1\&format=PDF

European Parliament and Council, 2000b. "Directive 2000/76/EC of the European Parliament and of the Council of 4 December 2000 on the incineration of waste." Official Journal of the European Communities L332/91. http://eur-lex.europa.eu/legalcontent/EN/TXT/PDF/?uri=CELEX:32000L0076\&from=EN

European Parliament and Council, 1999."Council Directive 1999/31/EC of $26^{\text {th }}$ April 1999 on the landfill of waste". Official Journal of the European Communities. L 182/1. http://eur-lex.europa.eu/legalcontent/EN/TXT/PDF/?uri=CELEX:31999L0031\&from=en

Gao, J, X Chen, and D Zheng. 2010. "Remanufacturing Oriented Adaptive Repair System for Worn Components." In 5th International Conference on Responsive Manufacturing Green Manufacturing (ICRM 2010), 13-18, Ningbo, China. doi:10.1049/cp.2010.0406.

Giuntini, Ron, and Kevin Gaudette. 2003. "Remanufacturing: The next Great Opportunity for Boosting US Productivity." Business Horizons 46 (6): 41-48. doi:10.1016/S00076813(03)00087-9.

Glavič, Peter, and Rebeka Lukman. 2007. "Review of Sustainability Terms and Their Definitions." Journal of Cleaner Production 15 (18): 1875-85. doi:10.1016/j.jclepro.2006.12.006.

Go, T., D. Wahab, M. Rahman, R. Ramli, and C. Azhari. 2011. "Disassemblability of End-ofLife Vehicle: A Critical Review of Evaluation Methods." Journal of Cleaner Production 19 (13): 1536-46. doi:10.1016/j.jclepro.2011.05.003. 
Gray, C, and M Charter. 2008. "Remanufacturing and Product Design." International Journal of Product Development 6 (3/4): 375 - 392. doi:10.1504/IJPD.2008.020406.

Gutowski, T, S Sahni, A Boustani, and S Graves. 2011. "Tire Remanufacturing and Energy Savings.” Environmental Science and Technology 45: 4540-47. doi:/10.1021/es102598b.

Hamzaoui-Essoussi, Leila, and Jonathan D Linton. 2014. "Offering Branded Remanufactured/recycled Products: At What Price?” Journal of Remanufacturing 4 (1): 1 - 15. doi:10.1186/s13243-014-0009-9.

Hazen, Benjamin T., Robert E. Overstreet, L. Jones-Farmer, and Hubert S. Field. 2012."The Role of Ambiguity Tolerance in Consumer Perception of Remanufactured Products." International Journal of Production Economics 135 (2): 781-790. doi:10.1016/j.ijpe.2011.10.011

Heil, J. P. 2011. "Study and Analysis of Carbon Fiber Recycling." Masters Thesis, North Carolina State University, http://repository.lib.ncsu.edu/ir/bitstream/1840.16/6885/1/etd.pdf

Howarth, Jack, Sada S.R. Mareddy, and Paul T. Mativenga. 2014. "Energy Intensity and Environmental Analysis of Mechanical Recycling of Carbon Fibre Composite." Journal of Cleaner Production 81: 46-50. doi:10.1016/j.jclepro.2014.06.023.

Ijomah, W. 2002. "A Model-Based Definition of the Generic Remanufacturing Business Process." PhD thesis, University of Plymouth. doi:10026.1/601.

Ijomah, W., M. Danis. 2012. "Refurbushment and reuse of WEEE" in Waste Electrical and Electronic Equipment (WEEE) Handbook. Edited by V. Goodship and Ab Stevels, 145$162 \mathrm{http} / / / \mathrm{www}$. sciencedirect.com/science/book/9780857090898

Ijomah, W., C McMahon, G Hammond, and S Newman. 2007. "Development of Design for Remanufacturing Guidelines to Support Sustainable Manufacturing.” Robotics and Computer-Integrated Manufacturing 23 (6): 712-19. doi:10.1016/j.rcim.2007.02.017.

Jahn, B, and E Witten. 2013. “Composites Market Report 2013," Federation of reinforced plastics, http://composites-germany.org/images/market-information/Market-Report2013.pdf.

Ke, Q., H-C. Zhang, G. Liu, and B Li. 2011. "Remanufacturing Engineering Literature Overview and Future Research Needs" in Glocalized Solutions for Sustainability in Manufacturing: Proceedings of the 18th CIRP International 437 Conference on Life Cycle Engineering, Braunschweig, Germany. Edited by J. Hesselbach and C. Herrmann, Springer-Verlag Berlin Heidelberg, 437-442 doi:10.1007/978-3-642-19692-8_75.

King, Andrew M, Stuart C Burgess, Winnie Ijomah, and Chris a Mcmahon. 2006. "Reducing Waste: Repair, Recondition, Remanufacture or Recycle?" Sustainable Development 267 (December 2005): 257-67. doi: 10.1002/sd.271. 
Lund, R. T. 1985. "Remanufacturing: The Experience of the United States and Implications for Developing Countries." UNDP Project Management Report No. 2, World Bank Technical Paper No.31, http://documents.worldbank.org/curated/en/1985/01/18526015/remanufacturingexperien ce-united-states-implications-developing-countries

Lund, R. T. 1996. “The remanufacturing industry: hidden giant”, BostonUniversity, Boston University Press, 7, 15-16.

Lund, R. T, and W.M Hauser. 2010. "Remanufacturing-an American Perspective." In 5th International Conference on Responsive Manufacturing - Green Manufacturing. Ningbo, China. 1-6 doi:10.1049/cp.2010.0404.

Marsh, George. 2009. “Carbon Recycling: A Soluble Problem.” Reinforced Plastics 53 (5): 22-27. doi:10.1016/S0034-3617(09)70149-3.

Matsumoto, M, and W Ijomah. 2013. "Remanufacturing" in Handbook of Sustainable Engineering, edited by Joanne Kauffman and Kun-Mo Lee: 389-408. Springer Netherlands, doi:10.1007/978-1-4020-8939-8.

Matsumoto, M, and Y Umeda. 2011. "An Analysis of Remanufacturing Practices in Japan." Journal of Remanufacturing 1 (1): 2. doi:10.1186/2210-4690-1-2.

Morin, Christelle, Anne Loppinet-Serani, François Cansell, and Cyril Aymonier. 2012. "Near- and Supercritical Solvolysis of Carbon Fibre Reinforced Polymers (CFRPs) for Recycling Carbon Fibers as a Valuable Resource: State of the Art." Journal of Supercritical Fluids 66: 232-40. doi:10.1016/j.supflu.2012.02.001.

Ogi, Keiji, Takashi Nishikawa, Yasutaka Okano, and Ichiro Taketa. 2007. "Mechanical Properties of ABS Resin Reinforced with Recycled CFRP." Advanced Composite Materials 16 (2): 181-94. doi:10.1163/156855107780918982.

OECD, 2015 "Municipal waste generation and treatment" https://stats.oecd.org/Index.aspx?DataSetCode=MUNW\# [accessed on 07/08/15]

Okayasu, Mitsuhiro, Tomohiro Yamazaki, Kohei Ota, Keiji Ogi, and Tetsuro Shiraishi. 2013. "Mechanical Properties and Failure Characteristics of a Recycled CFRP under Tensile and Cyclic Loading." International Journal of Fatigue 55: 257-67. doi:10.1016/j.ijfatigue.2013.07.005.

Oliveux, Géraldine, Luke O. Dandy, and Gary a. Leeke. 2015. "Current Status of Recycling of Fibre Reinforced Polymers: Review of Technologies, Reuse and Resulting Properties." Progress in Materials Science 72: 61-99. doi:10.1016/j.pmatsci.2015.01.004.

Perry, N., a. Bernard, F. Laroche, and S. Pompidou. 2012. "Improving Design for Recycling Application to Composites." CIRP Annals - Manufacturing Technology 61 (1): 151-54. doi:10.1016/j.cirp.2012.03.081. 
Pickering, S. J. 2006. "Recycling Technologies for Thermoset Composite Materials-Current Status." Composites Part A: Applied Science and Manufacturing 37 (8): 1206-15. doi:10.1016/j.compositesa.2005.05.030.

Pigosso, D., E. Zanette, A. Filho, A. Ometto, and H. Rozenfeld. 2010. "Ecodesign Methods Focused on Remanufacturing." Journal of Cleaner Production 18 (1): 21-31. doi:10.1016/j.jclepro.2009.09.005.

Pimenta, S, Pinho, S., 2012. "The Effect of Recycling on the Mechanical Response of Carbon Fibres and Their Composites." Composite Structures 94 (12): 3669-84. doi:10.1016/j.compstruct.2012.05.024.

Pimenta, S, Pinho, S., 2011. "Recycling Carbon Fibre Reinforced Polymers for Structural Applications: Technology Review and Market Outlook." Waste Management 31 (2): 378-92. doi:10.1016/j.wasman.2010.09.019.

Shi, Jian, Limin Bao, Ryouhei Kobayashi, Jun Kato, and Kiyoshi Kemmochi. 2012. "Reusing Recycled Fibers in High-Value Fiber-Reinforced Polymer Composites: Improving Bending Strength by Surface Cleaning." Composites Science and Technology 72 (11): 1298-1303. doi:10.1016/j.compscitech.2012.05.003.

Shi, Jian, Kiyoshi Kemmochi, and Li Min Bao. 2012. "Research in Recycling Technology of Fiber Reinforced Polymers for Reduction of Environmental Load: Optimum Decomposition Conditions of Carbon Fiber Reinforced Polymers in the Purpose of Fiber Reuse." Advanced Materials Research 343-344: 142-49. doi:10.4028/www.scientific.net/AMR.343-344.142.

Smith-Gillespie, Aleyn, Ben Peace, Ben Walsh and David Stewart, 2014. "Supporting Excellence in UK Remanufacturing” Workshop at Coventry University 1-14. http://www.carbontrust.com/media/627773/supporting-excellence-inukremanufacturing.pdf [Accessed on 07/08/2015]

Song, Young S., Jae R. Youn, and Timothy G. Gutowski. 2009. "Life Cycle Energy Analysis of Fiber-Reinforced Composites." Composites Part A: Applied Science and Manufacturing 40 (8): 1257-65. doi:10.1016/j.compositesa.2009.05.020.

Sundin, Erik. 2004. "Product and Process Design for Successful Remanufacturing." PhD Thesis, Linkoping Univeristy.

Suzuki, Tetsuya, and Jun Takahashi. 2005. "Prediction of Energy Intensity of Carbon Fiber Reinforced Plastics for Mass-Produced Passenger Cars." In Ninth Japan International SAMPE Symposium JISSE-9, Tokyo, Japan: 14-19 http://jt.0.007.jp/publications/051129/S1-02.pdf

Watson, M. 2008. "A Review of Literature and Research on Public Attitudes, Perceptions and Behaviour Relating to Remanufactured, Repaired and Reused Products." Report for the centre of remanfuactring and reuse, University of Sheffield. http://www.remanufacturing.org.uk/pdf/story/1p143.pdf 
Witik, Robert a., Remy Teuscher, Véronique Michaud, Christian Ludwig, and Jan Anders E Månson. 2013. "Carbon Fibre Reinforced Composite Waste: An Environmental Assessment of Recycling, Energy Recovery and Landfilling." Composites Part A: Applied Science and Manufacturing 49: 89-99. doi:10.1016/j.compositesa.2013.02.009.

Yang, Yongxiang, Rob Boom, Brijan Irion, Derk Jan van Heerden, Pieter Kuiper, and Hans de Wit. 2012. "Recycling of Composite Materials." Chemical Engineering and Processing: Process Intensification 51: 53-68. doi:10.1016/j.cep.2011.09.007.

Zuidwijk, R, and H Krikke. 2008. "Strategic Response to EEE Returns:" European Journal of Operational Research 191 (3): 1206-22. doi:10.1016/j.ejor.2007.08.004. 


\begin{tabular}{|c|c|c|c|}
\hline Authors & Industrial Sector & EOL terms & Discussion \\
\hline (Cheung et al. 2015) & Product design & $\begin{array}{l}\text { Remanufacture, recycle, } \\
\text { Refurbishment }\end{array}$ & $\begin{array}{l}\text { Remanufacturing, recycle, refurbishment not explicitly defined however, the three } \\
\text { strategies are clearly separated and references used define these terms accurately. }\end{array}$ \\
\hline (Ijomah and Danis 2012) & Electrical and Electronic & $\begin{array}{l}\text { Remanufacture, recycle, } \\
\text { re-use, repair, } \\
\text { refurbishment, recondition, } \\
\text { rebuild }\end{array}$ & $\begin{array}{l}\text { The definitions provided by the authors are the standard definitions outlined in } \\
\text { section 3.0. Refurbishment in this case is the same as recondition as defined by } \\
\text { British standard BS } 8887-2: 2009 \text {. It is also noted by the authors that within the IT } \\
\text { sector, rebuild is more likely to be used in exchange for remanufacture. }\end{array}$ \\
\hline $\begin{array}{l}\text { (Matsumoto and Umeda } \\
\text { 2011) }\end{array}$ & $\begin{array}{l}\text { Electrical and } \\
\text { Electronics (Japan) } \\
\text { Automotive (Japan) }\end{array}$ & Remanufacture & $\begin{array}{l}\text { The definition of remanufacture is in keeping with section 3, with case studies on } \\
\text { remanufacturing practices on photocopiers, engines, 'single use' cameras and ink / } \\
\text { toner cartridges in Japan. }\end{array}$ \\
\hline (Gray and Charter 2008) & $\begin{array}{l}\text { Aerospace, Electrical and } \\
\text { Electronic, } \\
\text { Automotive }\end{array}$ & $\begin{array}{l}\text { Remanufacture, recycle, } \\
\text { re-use rebuild, overhaul, } \\
\text { rewound, re-treaded, } \\
\text { recharged }\end{array}$ & $\begin{array}{l}\text { The definitions given in this instance are the standard definitions of recycle, } \\
\text { remanufacture, repair and recondition (section } 3 \text { ).. Re-use defined as directly used } \\
\text { again with no repairing Rebuild, overhaul, rewound, re-treaded, recharged also put } \\
\text { forward as industry specific terms for remanufacture. }\end{array}$ \\
\hline (Bakar and Rahimifard 2008) & Electrical and Electronic & $\begin{array}{l}\text { Remanufacture, recycle, } \\
\text { repair, reuse }\end{array}$ & $\begin{array}{l}\text { The authors in this present a graphical hierarchy outlines which clearly outlines the } \\
\text { differences between a remanufactured, recycled, repaired, and reused product. }\end{array}$ \\
\hline (Go et al. 2011) & Automotive & $\begin{array}{l}\text { Remanufacture, } \\
\text { reconditioning, reuse, }\end{array}$ & $\begin{array}{l}\text { Reuse defined as using EOL product directly, with remanufacturing adhering in } \\
\text { general terms to what is described in section } 3 \text {. Also, in this instance the authors are } \\
\text { not clear on the subtly differences between recondition and remanufacture and almost } \\
\text { lump both together. }\end{array}$ \\
\hline (Ke et al. 2011) & Industrial engineering & $\begin{array}{l}\text { Remanufacture, recycle, } \\
\text { reconditioning }\end{array}$ & $\begin{array}{l}\text { The definition of remanufacture is in general in keeping with section } 3 \text {, however, the } \\
\text { authors do not in general identify recycle and recondition as separate process from } \\
\text { remanufacture. That is, remanufactured products are stated as containing } \\
\text { reconditioned parts and remanufacture is also considered a recycling process }\end{array}$ \\
\hline (Gao, Chen, and Zheng 2010) & Aerospace & $\begin{array}{l}\text { Remanufacture, repair, re- } \\
\text { use }\end{array}$ & $\begin{array}{l}\text { Remanufacture is described in a tenuous way and do not acknowledge the accepted } \\
\text { standard that the performance of the product should be at least equal to as new } \\
\text { condition. Thus, no clear separation between terms is apparent. }\end{array}$ \\
\hline (Pigosso et al. 2010) & $\begin{array}{l}\text { Production engineering } \\
\text { (Eco design methods) }\end{array}$ & $\begin{array}{l}\text { Remanufacture, } \\
\text { refurbishment, reuse, } \\
\text { recycle, overhaul }\end{array}$ & $\begin{array}{l}\text { A general description of remanufacturing as with section } 3 \text { is documented in this } \\
\text { instance with the use of overhaul to describe remanufacturing also discussed. } \\
\text { However, the authors do not clearly separate refurbishing from remanufacturing. } \\
\text { That is, remanufacture products are said to containing refurbished parts within this } \\
\text { text. It is also the case, that reuse is defined as reusing directly and recycle is defined } \\
\text { as with section } 3 \text {. }\end{array}$ \\
\hline (Zuidwijk and Krikke 2008) & Electrical and Electronic & Remanufacture and recycle & $\begin{array}{l}\text { The authors in this instance cite EU directives to state what is meant by recycling } \\
\text { (see section } 3 \text { ). It is also the case that remanufacturing is also defined tenuously as, } \\
\text { "the recovery of components and products into 'as good as new' condition" }\end{array}$ \\
\hline
\end{tabular}

Table 1- Identifies some of the different ways in which the EOL terms are discussed within literature 


\begin{tabular}{|c|c|}
\hline Term/Theme & Operation \\
\hline Mechanical recycling of CFRP & Crushing, grinding and milling of CFRP. \\
\hline CFRP & $\begin{array}{c}\text { Removal of matrix via heat or chemical } \\
\text { treatment, leaving the fibres largely in tact }\end{array}$ \\
\hline Recycled CFRP & Implanting reclaimed or crushed fibres with \\
\hline Remanufactured fibres & $\begin{array}{c}\text { Name for the product created by conducting } \\
\text { mechanical recycling or fibre reclamation and } \\
\text { then impregnating fibres with new resin }\end{array}$ \\
\hline Remanufacturing course & $\begin{array}{c}\text { Name given by CFR to virgin fibres, obtained } \\
\text { as scrap or from excess via manufacturing } \\
\text { processes, which have been detangled, milled } \\
\text { and cut to create a usable product }\end{array}$ \\
\hline Remanufacturing subset of recycling & $\begin{array}{c}\text { Name given by Fraunhofer to a CFRP } \\
\text { repairing course offered }\end{array}$ \\
\hline $\begin{array}{c}\text { The remanufacture process is routinely } \\
\text { thought of as a sub set of the recycling } \\
\text { process }\end{array}$ \\
\hline
\end{tabular}

Table 2- Summary of the descriptions associated with recycling and remanufacturing terminology in CFRP industry 


\begin{tabular}{|c|c|c|c|}
\hline Level of effort & $\begin{array}{c}\text { Level of labour } \\
\text { involved }\end{array}$ & $\begin{array}{c}\text { Quality of warranty } \\
\text { given }\end{array}$ & $\begin{array}{c}\text { Product } \\
\text { performance }\end{array}$ \\
\hline Greatest & Remanufacture & Remanufacture & Remanufacture \\
\hline Neither greatest or least & Recondition & Recondition & Recondition \\
\hline Least & Repair & Repair & Repair \\
\hline
\end{tabular}

Table 3- Outlining the differences between a remanufactured, repaired and reconditioned product 
Virgin inputs

(energy or

Materials)

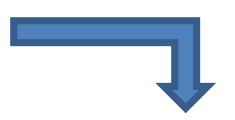

Materials

Processing

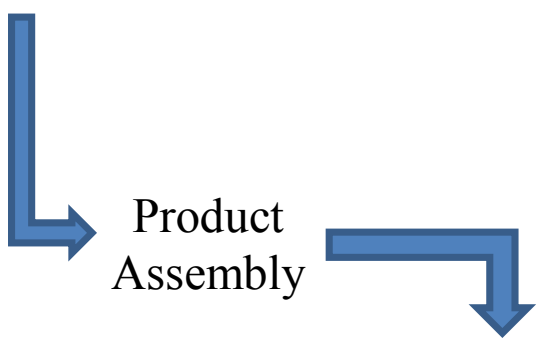

Finished

Product $\square$ Consumer

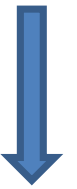

Landfill

Product

Discarded

\section{Recycle}

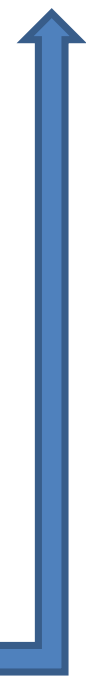

Figure 1-Recycle life cycle option 


\section{Clean}
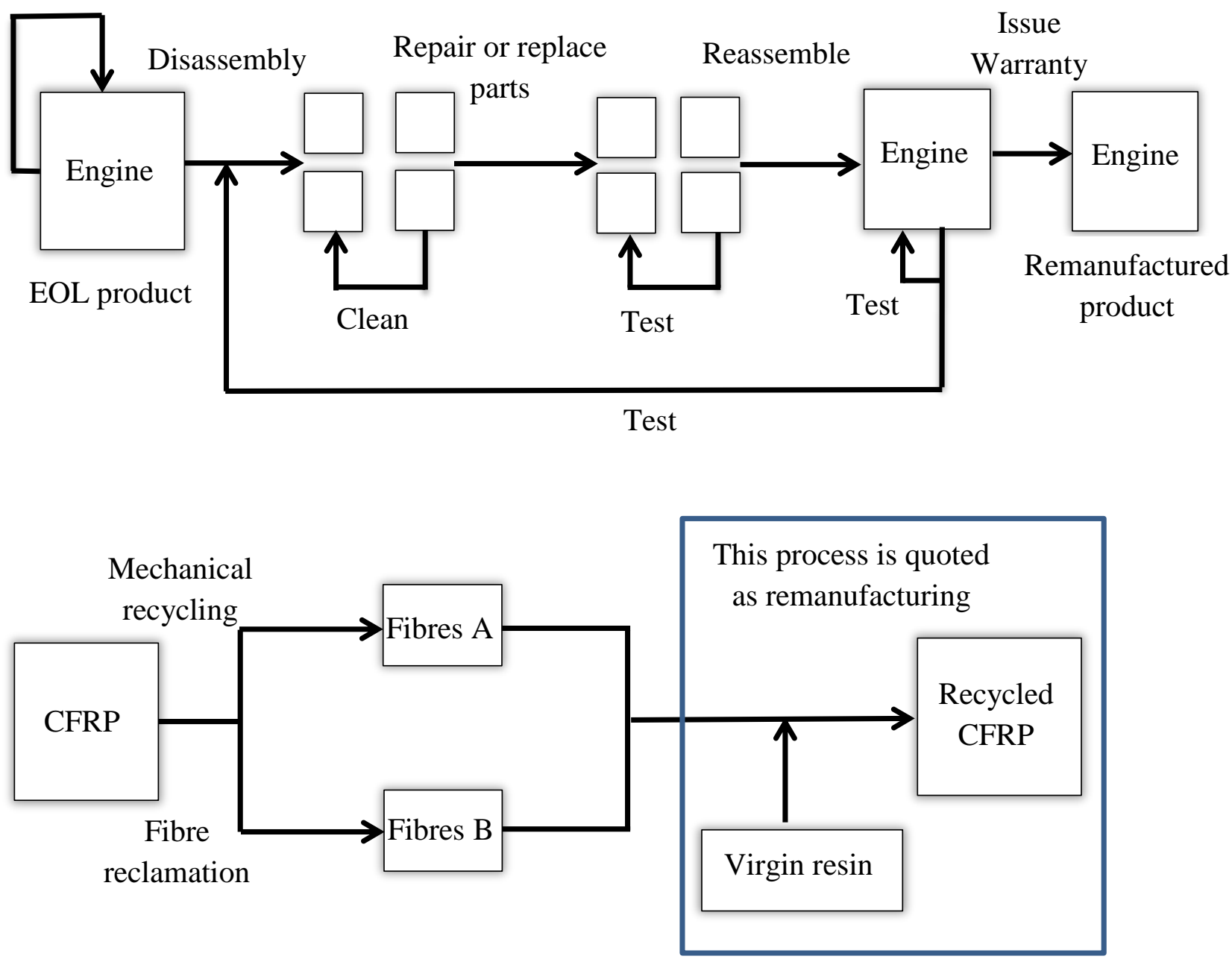

Figure 2 - Standard remanufacturing process carried out on an engine and the general remanufacturing process in relation to CFRP as described within literature. Noting that mechanical recycling will produce chopped and powered fibres with traces elements of resin, hence fibre $a$ and fibre $b$ denomination. 